\title{
Reasoning with the THOG Problem: A Forty-Year Retrospective*
}

\author{
María Dolores Valiña\#, Montserrat Martín \\ Department of Social Psychology, Basic Psychology and Methodology University of Santiago de Compostela, \\ Santiago de Compostela, Spain \\ Email: "mdolores.valina@usc.es
}

How to cite this paper: Valiña, M. D., \& Martín, M. (2021). Reasoning with the THOG Problem: A Forty-Year Retrospective. Psychology, 12, 2042-2069.

https://doi.org/10.4236/psych.2021.1212124

Received: October 8, 2021

Accepted: December 28, 2021

Published: December 31, 2021

Copyright (c) 2021 by author(s) and Scientific Research Publishing Inc. This work is licensed under the Creative Commons Attribution International License (CC BY 4.0).

http://creativecommons.org/licenses/by/4.0/

\begin{abstract}
Being able to create new information from already existing premises is the essence of human reasoning. This paper focuses on one of the most important experimental tasks that have been used to study how people make inferences: the THOG problem (Wason, 1977, 1978; Wason \& Brooks, 1979). It is a hypothetico-deductive reasoning problem in which subjects must formulate and test hypotheses from the comprehension of an exclusive disjunctive statement. Research on this task has shown that it is a difficult problem to solve and few people reach the logically correct answer. This paper presents some of the main theoretical explanations about people's inferences with this task. From a general perspective, the Dual Process and the Hypothetical Thinking Theories and the Mental Models Theory are found. Some of the more specific proposals have focused on analysing the underlying mechanisms of the cognitive biases such as the Confusion Theory or the Non-Consequential Thinking. Moreover, a review of the empirical investigations on this meta-inference task is presented. Finally, some research on the THOG problem that provides important new clues on broader topics in the study of human reasoning is analyzed.
\end{abstract}

\section{Keywords}

THOG Problem, Disjunctive Reasoning, Hypothetico-Deductive Reasoning, Dual Process Theory, Mental Models Theory

\section{Introduction}

Reasoning is one of the cognitive processes in which psychologists studying thought have shown interest. Knowing what type of mechanisms subjects use to ${ }^{\star}$ Part of this paper was presented at $21^{\text {st }}$ Conference of the European Society for Cognitive Psychology-ESCOP(25-28 September, 2019, Tenerife, Spain). 
elaborate a conclusion or studying which factors modulate inferences are some of the fundamental axes of empirical investigation on human inference.

Peter Wason, deemed one of the pioneers of modern Psychology of Reasoning, set forth a series of experimental tasks to study how problems that require planning, hypothesis proposal and consequence inference are solved (see for example Newstead, 2003 or Manktelow, 2021, for an excellent biography of P.C. Wason).

This work centres on one of these tasks: The THOG problem (Wason, 1977, 1978; Wason \& Brooks, 1979). Firstly it will be explained what this task consists of and which are the most common responses people give. Secondly, some of the main lines of investigation on the THOG problem will be analysed. Then, the main theoretical explanations on reasoning with this task will be set out. This work will also analyse how the study of reasoning has advanced from the empirical investigation of the THOG. The present retrospective study has been developed from the 1970s to the current decade.

The THOG is a hypothetico-deductive experimental task in which participants must reason according to an exclusive disjunctive rule and where they create and test hypotheses to reach the correct answer. The original version of the problem (Wason, 1977) is as follows:

In front of you are 4 designs: black diamond, white diamond, black circle and white circle (see Figure 1).
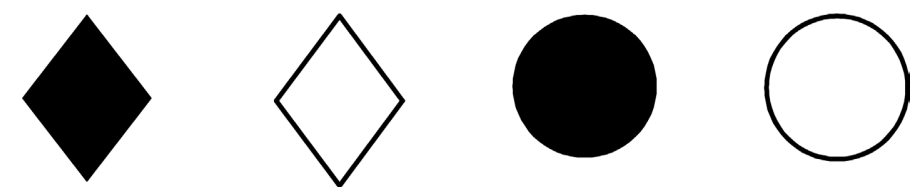

Figure 1. The THOG problem (the colours used in the original version were blue and red).

You are to assume that I have written down one of the colours (black or white) and one of the shapes (diamond or circle.) Now read the following rule carefully:

"If, and only if, any of the designs includes either the colour I have written down, or the shape I have written down, but not both, then it is called a THOG".

I will tell you that the black diamond is a THOG. Each of the designs can now be classified into one of the following categories:

a) definitely is a THOG,

b) insufficient information to decide,

c) definitely is not a THOG.

As had happened a decade before with another metainference task created by Peter Wason, the Selection Task (Wason, 1966), when the participants tried to solve the THOG, fewer than a third of them got the right answer, which was "the white circle is a THOG and the other two designs are not". To reach this response, participants have to start with the THOG example in the task statement 
(the black diamond is a THOG), and from that, create hypotheses on what the experimenter has written, taking the stated disjunction into account. The hypotheses are: 1) the experimenter has written white diamond and 2) the experimenter has written black circle. There follows a comparison of each hypothesis with the task designs. If the experimenter has written "white diamond", the design which may be a THOG is the white circle, since it is the only one with a characteristic that coincides. If the experimenter has written "black circle", the white circle will be the THOG too. Therefore, both hypotheses allow us to conclude that apart from the black diamond, "the white circle is also a THOG and the other two designs are definitely not".

The most commonly made biases are the "intuitive errors": Intuitive error "Type A" and "Type B" (Griggs \& Newstead, 1983). "Type A" intuitive error mirrors the correct response and leads to the answer "the white circle is not a THOG and the other two designs are THOGs". Intuitive error "Type B" occurs when subjects say: "the white circle is not a THOG and there is insufficient information to decide about the other two designs". Why are these answers repeatedly given? According to Wason \& Brooks (1979), these errors stem from the participants focusing on the task designs rather than on the hypotheses that must be elaborated based on what the experimenter has written. Therefore, people assume that the two properties of the designated THOG are the two properties included in the disjunctive rule.

Several theoretical explanations have been put forward about these errors, such as the "common element fallacy" and "perceptual matching bias". The "common element fallacy" consists in assuming that the two properties which define the positive example THOG ("diamond" and "black") are the properties of THOG, which leads to considering "white diamond" and "black circle" THOGs while "white circle cannot be THOG". The "perceptual matching bias" surmises that the participants respond to each design according to whether their properties match the positive example in the explanation or not. This would justify the frequent answer of "the white circle cannot be THOG" as it is considered completely unmatched.

Regardless of the explanation for the errors participants make, it is widely accepted by researchers that the THOG problem is a multitask one (Marek et al., 2000). In consequence, the main difficulty is that its correct solution calls for the use of several cognitive tasks, such as understanding an exclusive disjunction, generating hypotheses about possible combinations written by the experimenter and testing said hypotheses. Moreover, to reach the right solution, extra mental work is necessary as participants have to "think about what is true to find out what is false", or simultaneously consider alternative hypotheses which are mutually exclusive. In this vein, the THOG problem has been defined as a case of illusory inference related to exclusive disjunction and the problems that arise upon thinking about what is false (Manktelow \& Galbraith, 2012).

How can the complexity of this task be reduced? Empirical research in THOG has endeavoured to analyse what kind of variables might make it easier to reach 
the correct solution: Its content? Its structure? The scenario in which it is included? The type of instructions participants receive? And so on. In the following section some of the main empirical studies that have analysed these factors are presented. The objective is not to make an exhaustive review of them, but to put forward the main modulating variables of reasoning highlighted in the research on Wason's THOG problem (see Table 1).

\section{Looking for the Origin of Simplification: Beyond the Effect of Content}

Analysing the factors which explain reasoning with THOG and the keys to its difficulty has been and still is the driving force behind over forty years of empirical research (see Martín \& Valiña, 2002, 2003, for reviews on disjunction and the THOG problem, respectively).

One of the first explanations given about subjects execution said the difficulty of the problem lay in its abstract nature. The participant reasoned about an exclusively disjunctive rule which linked shapes and colours. This hypothesis led to the design of several thematic versions of the THOG with differing semantic content, in order to see if reasoning improved. This line of research had also been developed in the previous decade with another experimental task: the selection task, or four-card problem. However, empirical results have taken different routes (as regards the four-card problem, see, for example, Evans (2017): Chapter 1; Evans et al., 1993: Chapter 4; Manktelow, 2021; Newstead \& Evans, 1995 or Valiña \& Martín, 2016, for a review. See also Griggs, 1983, for a publication concerned with the role of problem content in the selection task and in the THOG problem). Specifically, the results of the first thematic versions of the selection task have been interpreted in terms of simplification for the content (Wason \& Shapiro, 1971; Johnson-Laird et al., 1972). Nevertheless, this effect is neither simply thematic nor is it necessarily a facilitator in the sense that it improves logical reasoning. In fact, "the thematic facilitation effect shows us the extreme sensitivity of reasoning or decision making to pragmatic factors" (Evans, 2000: p. 45). In this regard, the THOG problem and the Wason selection task "challenged the notion that human cognitive development culminates in a formal-logical stage" (Bellini-Leite \& Frankish, 2021: p. 207). In hindsight, today it is considered that the effect of thematic facilitation in the four-card problem may be oversimplified and imprecise (Evans, 2017). In general terms, the content looks like a critical factor for execution, but not in the way it has been interpreted on occasion.

Specifically, what has happened in the studies on the influence of content in reasoning with the THOG problem? The first results seem to indicate that this variable was not the key to ease reasoning, unless another kind of significant change in the task were made. For example, one of the first thematic versions that gave way to consistent facilitation (over $70 \%$ of participants got the right answer), was the "drug problem", proposed by Griggs \& Cox (1982), in which 
Table 1. Some empirical research concerning the THOG, in chronological order.

\begin{tabular}{lll}
\hline Authors & Version & Results-Explanation \\
\hline $\begin{array}{l}\text { Griggs \& Newstead } \\
(1982)\end{array}$ & $\begin{array}{l}\text { DRUG } \\
\text { Problem }\end{array}$ & $\begin{array}{l}\text { Facilitation: when the problem is phrased in such a way as to make } \\
\text { the structure of the task very clear and explicit. } \\
\text { Problem representation is key in problem solving. }\end{array}$ \\
$\begin{array}{l}\text { Newstead, Griggs \& } \\
\text { Warner (1982) }\end{array}$ & $\begin{array}{l}\text { GASTRONOMIC } \\
\text { Problem }\end{array}$ & $\begin{array}{l}\text { The realism of the task improves performance on the problem when } \\
\text { the realistic material cues in the correct answer from memory. }\end{array}$ \\
& Memory cuing explanation. \\
Smyth \& Clark (1986) & $\begin{array}{l}\text { HALF-SISTER } \\
\text { Problem }\end{array}$ & $\begin{array}{l}\text { Realistic content is not sufficient to induce correct answer. Express } \\
\text { the exclusive relation through a familiar and known concept } \\
\text { (half-sister) improve performance. }\end{array}$ \\
Girotto \& Legrenzi (1989) & $\begin{array}{l}\text { MIB-THOG Problem } \\
\text { SPY Problem } \\
\text { PUB Problem }\end{array}$ & $\begin{array}{l}\text { The generation of the hypotheses is not in itself sufficient to solve } \\
\text { the problem. } \\
\text { A plausible context for separating the levels (data and hypotheses) } \\
\text { can produce facilitation, even with the abstract original content. } \\
\text { Confusion Theory. }\end{array}$ \\
& $\begin{array}{l}\text { Facilitation: when the version separates positive instance from the } \\
\text { hypotheses and when subjects are required to generate hypotheses. }\end{array}$
\end{tabular}

$\begin{array}{ll}\text { Lea \& Freitag (1990) } & \text { BLACKBOARD Problem } \\ \text { Newstead \& Griggs } & \text { PUB Problem-reply } \\ (1992) & \end{array}$

Girotto \& Legrenzi SARS Problem

(1993)

Needham \& Amado (1995)

\author{
Griggs, Platt, Newstead \& THOG Problem \\ Jackson (1998) SARS Problem - Reply \\ Martín, Seoane, Valiña \& THOG Problem \\ Ferraces (1998) DRUG Problem \\ Marek, Griggs \& Koenig THOG Problem \\ (2000) "modified" \\ Valiña, Seoane, Martín, THOG Problem \\ Rodríguez \& Ferraces DRUG Problem \\ (2003) \\ PUB Problem \\ SPIES Problem \\ REPRIEVE Problem
}

Seoane, Valiña,

Rodríguez, Martín \&

Ferraces (2007)

Koenig \& Griggs (2011)

Schreiber (2014)
THOG Problem

ONE-OTHER THOG Problem

DRUG \& PUB Problems

PYTHAGORAS, BLACKBOARD \& SARS Problems

THOG Problem “modified”
Facilitation: separation positive instance from hypotheses and experimental instructions.

Sources of error: non-consequential reasoning and confusion theory.

Narrative thematic versions are easier to solve than the classic version.

Analogical transfer: participants may have abstracted the solution principle from the Pythagoras problem to the THOG problem.

Key of facilitation: attentional factors (via experimental instructions).

Performance is modulated by individual differences

Correct performance increased reducing cognitive complexity of the task and the possibility of non-consequential thinking.

Better performance with thematic content than with abstract content.

Better performance with one-other instructions than with standard instructions.

Individual differences.

Keys: Individual differences in flexibility and cognitive abilities.

Performance with the THOG problem is explained by the dual process theory.

Subjects rely on visual symmetry when solving the THOG problem. 
participants had to discover a combination of medication in function of a determined medical treatment. The best performance with respect to the original abstract THOG was explained in terms of problem representation. The underlying structure of it seemed to indicate the need to consider two possibilities, which corresponded to the two hypotheses needed to reach the solution. Despite criticisms received concerning structural differences between the THOG problem and that of drugs, the authors defended that the tasks were about isomorphic ones which required the same logical operations to get the same answer.

One of the first works in which the influence of empirical knowledge on reasoning with the THOG became evident was that of Newstead et al. (1982). In particular, the authors devised "the gastronomic problem", in which different kinds of solid food (meat or ice cream) and sauces (gravy or chocolate sauce) were related. The task consisted of the following: the experimenter tells the participants that they will eat a meal if it includes one of the foods written down by a friend of theirs: a solid (either meat or ice-cream), and a liquid (either gravy or chocolate sauce), but will not eat meat with chocolate sauce or ice-cream with gravy. Knowing that the experimenter eats meat with gravy, the participant must decide which other combinations are acceptable for consumption. The results indicate that a high number of participants gave the right answer: "the experimenter can eat ice-cream with chocolate sauce and not meat with chocolate sauce or ice-cream with gravy".

However, the key variable seemed to be the activation of knowledge of the participants recalled from the content, since the right answer coincided with a more plausible one empirically speaking. This statement was confirmed in a later experiment in which said version was solved successfully ( $75 \%$ of cases) by children of 8 - 9 years old, which, according to Piaget, still do not seem to have the formal skills needed to solve these kinds of problems. In line with this and in the same year, Griggs \& Cox (1982) proposed the "memory cuing hypothesis", to explain the execution with a thematic version of the four-card task, which included a "drinking age rule" ("if a person is drinking beer then the person must be over 19 ”). The authors pointed out as a key factor of the registered facilitation, the activation of empirical knowledge and past experience to generate the solution, since the correct answer coincided with the most coherent one on an empirical level. A similar strategy could be used by participants in the case of the gastronomic version of the THOG. Then, are experience and knowledge the keys of performance?

The realism of the relation included in the task could be an important variable, but not always enough to facilitate making the correct choice. Along these lines, Smyth \& Clark (1986) came up with a new thematic version ("the half-sister problem") in which an everyday disjunctive expression was used: the concept of half-sister (a woman who shares either the mother or the father, but not both). The authors showed participants the names of four women and their parents. They were told that one of them, Robin, was the experimenter's half-sister and were asked 
which of the other three were also half-siblings. 95\% of participants got the correct answer. However, this problem has been criticised for being considered more of a test of classification than an isomorphic reasoning to THOG. In fact, when presented with the same version as in the THOG, the execution worsened. Therefore, it seemed that neither the task content nor the realism of relation included in the rule was enough to lead participants to develop the right strategy.

In the late eighties, research using abstract versions of the THOG that also registered facilitation started to be designed. In this vein, Girotto \& Legrenzi (1989) devised new thematic and abstract versions of the task so as to confirm what for them was fundamental to come to the right answer: the need to separate two levels, data and hypothesis. This is the essence of "Confusion Theory". In particular, the origin of facilitation is in the differentiation between the level of data (that is, the THOG example which is mentioned in the explanation) and the level of hypothesis that the experimenter has elaborated from the THOG pointed out. According to the authors, this is crucial in reaching the correct answer, both in thematic versions ("the Soviet Spies problem" by Girotto \& Legrenzi, 1989, "the Blackboard Problem" by O’Brien et al., 1990, "the Pythagoras Problem" by Needham \& Amado, 1995), as well as abstract ones ("the MIBTHOG Problem", "the Pub Problem", the TRUMP-FAFNER Problem, "the One-Other THOG Problem", "the SARS Problem", "the SARK Problem") (see Table 1). In consequence, according to "confusion theory", intuitive errors occur because participants have difficulties in separating the data given in the problem (i.e., the values of the identified THOG) from the hypotheses to be generated (i.e., the possible written-down combinations).

From a more general perspective, some authors propose studying the THOG problem trying to eliminate the unnecessary barrier between reasoning research and the more general study of thought (Evans, 2010). In this sense, the way of reasoning with the THOG problem has been related to other types of thinking, such as decision making and participants' own cognitive limitations. Thus, the difficulties in reasoning with disjunctions can also be linked to difficulties in the decision making process. Along these lines, Shafir \& Tversky (1992) propose that when participants decide upon everyday issues, they frequently fail to consider all the possible results and consequences of uncertain events. This occurs, for example, in the "disjunction effect" (Tversky \& Shafir, 1992), according to which people prefer to rely on one decision in which a mental simulation is involved, rather than two, even if both lead to the same conclusion. This is proposed in the "non-consequential reasoning hypothesis" by Girotto \& Legrenzi (1993). In this sense, incorrect performance of the task could be modulated by the difficulties of thinking through uncertainty (Newstead \& Griggs, 1992; Newstead et al., 1995). In summary, problems may arise when having to combine possible hypotheses and test them using a disjunctive rule. From this hypothesis participants' errors are linked to limitations in working memory and attention.

Following Stanovich (2011), only those subjects of higher ability can decouple 
their beliefs and previous knowledge from the problem content in order to think hypothetically about complex problems. How can participants' cognitive capacity influence experimental task solving such as the THOG? Two lines of research that have analysed this question are:

1) On the one hand, the role of attention on performance, manipulating the type of experimental instructions participants receive. Empirical studies such as those by O’Brien et al. (1990); Newstead \& Griggs (1992); Griggs et al. (1998), Marek et al. (2000); Valiña et al. (2003), among others, analysed the importance of focussing attention on experimental instructions on the execution of the THOG. Some studies compare participants' reasoning with standard instructions (of the classification of the THOG designs) against "one-other" instructions, in which participants are asked directly: "in addition to the black diamond, one other design is a THOG. Which other design is a THOG?”. In other works, instructions centred on trying to make the participant focus their attention on other questions that also seemed key in the execution. For example, facilitating the separation of levels (data and hypothesis) or explicitly requiring participants to make hypotheses.

2) On the other hand, the role of individual differences in task solving has been studied (this line of investigation is further developed in the next section).

\section{The Study of Individual Differences and the THOG Problem}

The main object of pioneering studies on individual differences in the THOG (Mimikos, unpublished, cited in Newstead \& Evans, 1995) was to analyse differences in execution among participants with differing education, such as students of science and art. Nevertheless, as of the nineties, researchers such as Bruckmaier et al. (2021); Evans et al. (2008); Martín et al. (1998); Oberauer et al. (2007); Ricco et al. (2020); Rojas-Barahona et al. (2021); Seoane et al. (2002); Seoane et al. (1997); Seoane et al. (2007); Stanovich (1999, 2004, 2011, 2018, 2021a); Stanovich et al. (2004); Stanovich \& Toplak (2012); Stanovich \& West (1997, 1998, 2000); Stanovich et al. (2011, 2016, 2017); Thompson \& Markovits (2021); Toplak \& Rizeq (2020); Toplak \& Stanovich (2002); Valiña et al. (2003); Valiña et al. (1995, 2000); West et al. (2008), started studying the link between the participants' cognitive skill and its implementation in different experimental reasoning tasks. In effect, people differ in their cognitive capacity, which is echoed in the marks they obtain in psychometric intelligence tests.

Is there a relation between these marks and the execution of experimental reasoning tasks like the THOG? Martín et al. (1998) analyse this question. In this work, participants had to solve two experimental tasks: the original abstract THOG and a thematic version of it: "the Drug Problem". The subjects also performed several psychometric tests that measured comprehension and reasoning capacity. Results indicated that both reasoning and comprehension 
modulated the execution in both versions of the THOG. Additionally, the thematic version registered better results than those of the abstract original. In later works (Valiña et al., 2003; Seoane et al., 2007) the authors increased the parameters that could explain the execution in the THOG. Not only cognitive capacity and skills, but also variables related to personality and "dispositional trends" seemed to influence reasoning. In particular, Seoane et al. (2007) analysed, on the one hand, the influence of characteristics related to the task itself (content and instructions) and on the other hand, the differential characteristics of the participants. The experimental tasks used were two thematic versions of the THOG: "the drug problem" (Griggs \& Newstead, 1982) and "the pub problem" (Girotto \& Legrenzi, 1989), as well as two abstract versions depending on the type of experimental instructions. Participants received the original version, with "standard" instructions or "one-other instructions"). Results confirmed main effects of both variables, content and instructions, but no interactive effects. "The pub problem" in particular, showed better execution than "the drug problem" and the "one-other" instructions obtained better results than the standard ones in the original version. Furthermore, a differential execution by participants was registered when solving the THOG versions. The empirical results indicated that differences in processing capacity were not enough to explain the execution.

In line with Stanovich (1999), the performance was explained not only from computational level differences (algorithmic), but also from differences in intentional level. In particular, verbal reasoning, the ability to understand and solve logical problems or cognitive flexibility turned out to be good predictors of individual differences in reasoning the THOG. Consequently, the execution could not only be explained by differences in participants' cognitive capacity and abilities, but that other variables linked to styles or "thinking dispositions" were also important parameters. The results of these empirical works confirm the proposal by Stanovich $(1999,2009,2011)$ and Stanovich \& West $(2000)$, who defended the need to explain differential execution in reasoning tasks from different levels of analysis (algorithmic and intentional).

Thus far, the different variables that seem to influence reasoning with the THOG task have been presented. Regardless of what these factors are, when participants guess the designs which are THOG or not, in general terms, it is said that there is facilitation. Nevertheless, "we only know they answered correctly, not what led to that answer" (Koenig \& Griggs, 2011: p. 66). In the next section, a line of research on the THOG is presented. This work analyses which could be the key components of the task that lead to facilitation, using the analogical transfer method.

\section{Searching for the Origin of Facilitation: The Research on Analogical Transfer}

Griggs et al. (2001); Koenig \& Griggs (2001, 2004a, 2004b, 2011); Koenig et al. 
(2007) started a line of empirical investigation into whether participants were able to isolate the start of a solution to a version of the THOG and use this knowledge to solve the original problem. One of the tasks used is the "Pythagoras THOG problem" (Needham \& Amado, 1995). This task included the same dimensions (colour and shape) of the figures as the THOG problem in a narrative context which separated data and hypothesis, and asked participants to make hypotheses about colour and shape combinations a teacher may have written down. The authors propose that the narrative structure is responsible for facilitation (62\% correct answers), as it allows for data-hypothesis separation. However, the explicit requirement for hypothesis generation did not improve reasoning (as had previously been proposed by Girotto \& Legrenzi, 1993; Newstead \& Griggs, 1992; Smyth \& Clark, 1986 or Wason \& Brooks, 1979). From critical positions it was expressed that the key to the Needham \& Amado task was the inclusion of a new characteristic to the problem which had not been contemplated and that could affect results. This was later analysed by Griggs et al. (2001). In particular, in "the Pythagoras problem", the designs were numbered "Figure 1", "Figure 2", "Figure 3" and "Figure 4". This meant that "Figure 1 is a THOG" was used instead of "the black diamond is a THOG", as in the original version. The line of research put forward by Koenig \& Griggs (2004a, 2004b) proposes that, for participants to understand the problem and transfer this knowledge to finding the correct solution for the original THOG, the version used must fulfil two requirements: 1) allow for the separation between the THOG example and the hypotheses on the possible combinations written by the experimenter, and 2) explicitly ask participants to make hypotheses. Koenig \& Griggs (2004a, 2004b, 2011) and Koenig et al. (2007), designed a series of studies with different versions of the THOG (such as the "standard dot-cross THOG problem" or "standard letter/number THOG task" (Cordell, 1978), to analyse factors responsible for transfer. Specifically, they analysed the following question: To get the answer, do the participants use heuristic strategies based on superficial similarities of tasks, or is the similarity in problem structure the key factor? Results seem to indicate that the critical variable was the structural similarity among the tasks used.

In general terms, the empirical results within this line of analogical transfer research support dual process theory (Evans \& Over, 1996). Following Koenig et al. (2007), the analogical transfer and the dual-process theory explain facilitation on the THOG task. This theory approach, developed in the following section, proposes the existence of two systems or forms of reasoning: system 1, which include quick implicit and automatic processes (type 1 processes) and system 2, consisting of slow explicit processes that require effort (type 2). The latter is responsible for hypothetical thinking and allows for the isolation of the start of the solution of the THOG, which in turn facilitates success in process transfer. The following section sets out the main theory explanations on THOG reasoning and analyses this theoretical proposal. 


\section{Thinking about the THOG: Main Theoretical Explanations}

On a theory level, several different explanations about THOG reasoning have been proposed. Some of the more specific ones have focused on analysing the origin of the errors, such as the already explained "common element fallacy" or "perceptual matching bias". In fact, much can be known about human reasoning by studying them (Evans \& Over, 1996). From a more general perspective, in the context of theories about human inference, among the theoretical proposals that have dedicated most attention to THOG reasoning, we find the Dual Process and Hypothetical Thinking theories (Evans \& Over, 1996; Evans 2003, 2007; Evans et al., 2003). The Mental Models Theory has explained the difficulty of reasoning with disjunctions in studies on illusory inferences (Johnson-Laird \& Savary, 1996, 1999; Khemlani \& Johnson-Laird, 2017). Specifically, in this historical context, an old student of Princeton University, Mark Johns, has proposed an explanation for the execution with the THOG (see Johnson-Laird, 2000). This approach is set out below.

\subsection{The Mental Models Theory}

The Mental Models Theory (Johnson-Laird, 1983; Johnson-Laird \& Byrne, 1991, 2002; Johnson-Laird, Byrne, \& Schaeken, 1992) proposes that participants reason by elaborating semantic representations from the meaning of the premises and using their general knowledge of the world. In short, they construct mental models. This is explained in three points as follows. Firstly, the general phases of a deduction are presented, focusing on reasoning with an exclusive disjunction. Secondly how Mental Models Theory proposes THOG problem reasoning is explained. Lastly, how this theory explains the influence of knowledge on reasoning is analysed, from the effect of modulation as well as cognitive illusions. These two are lines of investigation developed in this theory's framework (see Johnson-Laird, 2000, 2012, 2013, 2021; Johnson-Laird et al., 2018; Johnson-Laird \& Khemlani, 2013; Khemlani \& Johnson-Laird, 2009; 2017; Quelhas \& Johnson-Laird, 2017).

The starting point for a deduction is the participants' understanding of the meaning of the premises shown in the task, supported by their understanding of the world, to create a mental model that represents a state where the statements are true. Below is a provisional and possible conclusion, which is true in the constructed model and must be validated. That is, possible counterexamples which make it false have to be searched for. If none exist, inference will be definitively validated and accepted, and if a counterexample exists, said conclusion will be rejected and another created.

According to Mental Models Theory, errors made by participants are not momentary lapsus, but are linked to cognitive limitations on a working memory level. In this vein, one of the main predictions of the theory is that the higher the number of models the participant has to reason, the higher the working memory load, increasing the possibility of making mistakes. Hence, participants tend to 
initially reason about the least amount of information possible. Only in the case of not being able to reason from the initial explicit model do they develop or use implicit models, fleshing out all the alternative possibilities. A consequence of the previous prediction is the principle of truth, according to which participants only initially contemplate models that express situations in which the premises are true, which in turn minimises working memory load. However, this may be an added difficulty in disjunctive reasoning, where the participant needs to "think what's false". In effect, disjunctions are difficult, and their difficulty lies in that having reasonable intuitions about them is complicated (Johnson-Laird et al., 2012). To correctly reason it is necessary to keep in mind models of more than one possibility, and to represent what is true as well as untrue, thinking about these possibilities consciously. In other words, participants should not rely on just one mental model, but on models spears out in a series of possibilities. In this sense, reasoning depends on intuitions or on deliberations and fully explicit models or both (Johnson-Laird, 2021; Johnson-Laird et al., 2021).

It has been shown that inferences from an inclusive disjunction are more difficult than those from an exclusive disjunction. In the following section we see how this theory explains reasoning with exclusive disjunction, which is the type of rule participants reason in the THOG problem.

From the statement "p or q but not both", the participant represents two initial explicit models, which are the following:

q

If necessary, the fleshed out models would be:

$\begin{array}{ll}\mathrm{p} & \neg \mathrm{q} \\ \neg \mathrm{p} & \mathrm{q}\end{array}$

where " $\neg$ " represents the negation of a clause.

Focusing on the THOG problem and the Mental Models Theory framework, an old Princeton University student, Mark Johns, developed a computer program to explain the reasoning behind this task (Johnson-Laird, 2000). The explanation is as follows:

From the initial information in the formulation: "black diamond is a THOG", participants envisage the two characteristics the experimenter has written, and following the "principle of truth", construct the mental models that represent them:

black

diamond

It is then incorrectly inferred that "the white diamond may be a THOG", as it shares one of those characteristics, but they cannot be certain since the other characteristic (black), might be critical. For the same reason, they could infer that "the black circle may be a THOG" as it shares one characteristic, but they also answer that the white circle cannot be a THOG because it shares neither characteristic.

The correct answer depends on fleshing out the initial models to make explicit 
what is false, in both cases:

$$
\begin{array}{ll}
\text { black } & \neg \text { diamond } \\
\text { ᄀblack } & \text { diamond }
\end{array}
$$

Since there are only two possible shapes and two possible colours, the false cases in both models could be replaced by their corresponding positive characteristics:

$$
\begin{array}{ll}
\text { black } & \text { circle } \\
\text { white } & \text { diamond }
\end{array}
$$

A design is THOG if it has one of the characteristics in each one of those models, and is indeterminated (could be or not) if it has one characteristic in only one of the models. It follows that "the white circle is a THOG" because it has one characteristic from the first possibility and one from the second. Furthermore, neither "the black circle" nor "the white diamond" are THOGs because the former has both characteristics from the first possibility and the latter has both from the second.

Research into the THOG has revealed that when participants reason with different thematic versions of the task, answers may vary. Content type, scenario, empirical knowledge and so on are key variables in the execution. For years, one of the criticisms of the mental models theory focussed on the lack of specificity as regards the sort of mechanisms that could determine the role of those factors on reasoning. Thus, Johnson-Laird \& Byrne (2002) have proposed the strategies of semantic and pragmatic modulation, which can have two different effects on reasoning: 1) add links between models or 2) block the activation of counterexamples. Initial research into the effect of modulation has been performed in the area of the conditional "if...then" (see, for example Quelhas et al., 2010), even though later, the importance of knowledge on reasoning has also been studied in other connectives such as conjunction, disjunction (see for example López Astorga, 2018, 2019; Quelhas \& Johnson-Laird, 2017; Quelhas et al., 2019; Johnson-Laird et al., 2021), or the negation of said connectives (Khemlani et al., 2014; Macbeth et al., 2014; Yin et al., 2000, among others).

In this sense, Quelhas and Johnson-Laird (2017) have empirically confirmed the existence of differences in the interpretation of the disjunction "or", depending on the content in the formulations and participants' empirical knowledge. In effect, "knowledge modulates the meanings of logical terms" (Johnson-Laird, 2021: p. 221). According to the authors, the disjunctive connective has a key meaning, which leads to an inclusive interpretation. Nevertheless, modulation can affect this interpretation and give way to three different interpretations: exclusive, forward (the first premise implies the second) and backward (the second premise implies the first). As a consequence, the inferences participants judge valid may depend on the possibilities the premises refer to. Since modulation might change these possibilities of one type of interpretation to another, the type of disjunctive inference devised could also be modified.

The basic proposals of the mental models theory predict and explain infe- 
rences from disjunctions that are systematically false. In that sense, and to reduce the load on working memory, on occasion participants develop procedures that lead them to erroneous conclusions. These errors are "illusory inferences" which may look convincing illusions as they are made when reasoning with connectives such as disjunction (see Pohl, 2017, for a publication on cognitive illusions in thinking). More specific studies on the role of illusions in reasoning are, for example, Johnson-Laird (2006); Johnson-Laird \& Savary (1996, 1999); Khemlani et al. (2009, 2017); López Astorga (2014); Sablé-Meyer, \& Mascarenhas (2021); Santamaría \& Johnson-Laird (1998, 2000). Thus, one of the lines of research of the last decades in the mental models theory revolves around studies on illusory inferences and how they can be reduced or eliminated. For example, Khemlani et al. (2009: experiment 3) asked participants to make an added inference from the premises, in order to help them think about what is true as well as what is false. For their part, Santamaría and Johnson-Laird (2000) have proposed an "antidote" for illusory inferences. This entails reasoning from disjunctions of physical objects (such as newspaper advertisements), rather than disjunctions based on the truth values of assertions (see also Carriedo et al., 1998; Johnson-Laird \& Savary, 1996, 1999; Khemlani \& Johnson-Laird, 2017).

The existence of illusory inferences "appear to be a decisive test for the use of mental models, because no other current theory predicts their occurrence" (Khemlani \& Johnson-Laird, 2009: p. 618). From a wider perspective, the study of these types of inferences is very exemplifying as it helps advance in more general questions in reasoning, such as the nature of human rationality. In effect, the THOG problem, defined as "a case of illusory inference" (Manktelow \& Galbraith, 2012: p. 117) has been and still is a useful tool to analyse broader questions in reasoning, such as the debate about human rationality (see for example Viale, 2021), or the study of individual differences (see for example Oberauer et al., 2007, in which authors proposed that individual differences in working memory capacity are a good predictor of reasoning ability).

The Theory of Mental Models has stated the principle of truth as a key to be able to explain both the difficulties in reasoning with disjunctions and the illusions in reasoning themselves. However, other authors question said principle, since participants can easily and accurately represent false possibilities, if instructed to do so (Evans et al., 2003). In this respect, from different theory perspectives, other principles have been proposed to explain hypothetical thinking. In this context, the following section presents the heuristic-analytic theory, the dual process theory and the hypothetical thinking theory.

\subsection{The Heuristic-Analytic Theory, Dual Process Theory and the Hypothetical Thinking Theory}

Dual Process Theories are well known in many fields of psychology (see Ball \& De Neys, 2018; Evans, 2008, 2012, 2018; Frankish \& Evans, 2009, for reviews). Focusing on the psychology of reasoning and following Evans (2004), the two 
roots of the modern dual process theories (Evans, 1989; Sloman, 1996; Stanovich \& West, 2000) are the journal article written by Wason \& Evans (1975) and the “Two-Factor Theory” (Evans, 1982).

Wason \& Evans (1975) tried to explain the reasoning behind another metainference task also devised by Peter Wason: the selection task (Wason, 1966, 1968). The authors observed discrepancies between participant's execution and the explanations given about how they had solved the task. According to these authors, the differences were due to the activation of two cognitive processes: type 1 and type 2. Type 1 processes select aspects relevant to the task preconsciously, according to linguistic, semantic and/or pragmatic keys. Type 2 is explicit and conscious reasoning processes that develop from previously selected information.

The two-factor theory is based on the results obtained by Evans (1972a, 1972b, 1977) with another conditional paradigm: the negations paradigm. These papers revealed the influence of logical and non-logical factors on reasoning. But "this theory is descriptive and provides no real explanation of the cognitive processes that underlie our observations" (Evans, 2021: p. 124).

Later, Evans $(1984,1989)$ broadened the previous explanation in the Heuristic-Analytic Theory (see Evans, 2004, 2008, 2013, for reviews). This theory is a bridge between the two roots described above and the dual process theory of Evans \& Over (1996). Evans $(1984,1989)$ explained the origin of reasoning bias via heuristic processes. The analytic processes were initially "mysterious" and related to the deductive competence. In this theory, heuristics are preconscious and their function is to selectively represent relevant information, retrieve and add knowledge from memory. Then, subjects reason with these personalized representations. In this context, participants might make mistakes if they choose logically irrelevant information or do not take relevant information into account when reasoning about it in a second analytical phase. In a review of this early heuristic-analytic theory (Evans, 2006, 2007), it is stated that said errors not only occur in the heuristic phase, as defended in the initial version, but also occur during the later explicit reasoning process. Therefore, both types of processing, heuristic and analytic, could be influenced by the participants' beliefs, empirical knowledge or experience. Specifically, Evans (2006) presents the "fundamental heuristic bias" and the "fundamental analytic bias" in order to explain the role of type 1 and type 2 processing in the causes of cognitive biases. In this sense, following Stanovich (2011), the activation of Type 2 thinking was not a guarantee of normative success. At the same time, the "search for counterexamples" and "fleshing-out implicit models" proposed by the mental models theory, might account for analytic reasoning (Evans, 2004).

Let us return to the THOG problem, in order to develop how the Heuristic-Analytic Theory explains reasoning with this experimental task. The type 1 or implicit processes are responsible for the activation of heuristic strategies such as attentional heuristics that may lead to, for example, "intuitive error" in the 
THOG. Specifically, heuristic processes focus on black and diamond as relevant characteristics from the example THOG and both will be decoded into a single mental model of the hypothesis. This model must be rejected by explicit analytic reasoning, in order to find the correct answer. Likewise, participants can automatically activate pragmatic keys which contextualise the problem from beliefs, empirical knowledge etc. "Decontextualisation" is precisely a function of system 2 , which focuses on reasoning from the structure of the task, overcoming pragmatic inferences derived from system 1 . Type 2 processes are explicit, conscious, specifically human, limited by processing capacity and linked to general intelligence. They are responsible for abstract, analytic and hypothetico-deductive reasoning, required by the formal solution to the THOG. In particular, this type of reasoning leads participants to make hypotheses on what the experimenter has written, compare them to existing designs and explicitly evaluate the answer.

Hypothetical thought involves a process of mental simulation through the imagination of possibilities and the exploration of their consequences (Evans 2007, 2019). A theoretical framework which includes the approaches of dual process theories and explains the THOG problem execution is the Theory of Hypothetical Thinking (Evans, 2007, 2019; Evans et al., 2003). The basic idea posits that participants create mental simulations to analyse possibilities, both in reasoning and decision-making processes. Both are modulated by three principles:

1) the principle of singularity, considers that participants construct one mental model at a time, which expresses a hypothetical situation,

2) the principle of relevance: the model represented will be the most relevant one on a pragmatic level and

3) the principle of satisfaction: this representation is subject to an explicit (analytic) evaluation that is accepted if satisfactory.

According to the principle of singularity, participants considered only one possibility at a time, but that does not mean they cannot think of other models, for example, contemplating the consequences of alternative choices in decision-making. It is nevertheless difficult to consider other hypotheses, especially if it has to be done simultaneously. Specifically, the THOG problem requires two hypotheses to be considered. One of the theoretical explanations around the difficulty of the THOG focussed precisely on this approach. It involves the non-consequential reasoning hypothesis, developed in a previous section (Newstead \& Griggs, 1992; Newstead et al., 1995).

Regarding the principle of relevance, participants choose to represent the most prominent model on a pragmatic level. This contextualisation of the task relies on empirical knowledge and experience, and is an adaptive process, which can lead to either generating thematic facilitation or errors on a formal level. In this vein, Stanovich (1999) defined "the fundamental computational bias" as a powerful tendency to contextualise problems and decisions from previous knowledge, occasionally giving formally wrong answers. According to Stanovich 
\& West (2000), system 2 aims to suppress the automatic contextualisation of the problem. It is therefore responsible for the process of "cognitive dissociation" (Stanovich, 2009), necessary to reach the logically correct solution in tasks such as the THOG, where the normative answer requires the suppression of pragmatic influences or cognitive illusions.

According to Evans (2006), one of the most fascinating aspects of human cognition is the ability to make suppositions, that is, temporary beliefs which are the basis of a mental simulation of a possible scenario. However, “... it is essential that such suppositions be represented within epistemic mental models that encode their hypothetical nature" (p. 386). Therefore, to make sure the formally correct answer is given, it is necessary to develop an abstract and analytic reasoning, which allows for the explicit evaluation of the answer, accepting it if satisfactory (principle of satisfaction). As Stanovich et al. (2011) suggested, to reason hypothetically, the participant must have a critical cognitive capacity that allows them to differentiate between representations in the real world and those in imaginary situations. He must discriminate between the representation of an action and that of alternative potential actions, in the development of cognitive simulations.

The Dual Process Theory (Evans \& Over, 1996) explains the interaction between processes 1 and 2 in the development of human thinking and both the correct execution as well as errors made is justified. In general terms, the existence of dual processes or systems of thought is "one of the most widespread and influential theoretical ideas in contemporary cognitive psychology" (Rhodes et al., 2020: p. 185).

\section{Conclusion}

This work has aimed to analyse why the THOG is such a difficult experimental task to solve and present the main theoretical approaches and lines of empirical research that have tackled this question.

One of the most frequently accepted conclusions by researchers studying the THOG is that there is no unanimous agreement on the origin of the task's difficulty or, at the very least, on the key modulating parameters of the execution. On one hand, reasoning with this task revealed biases strategies in individuals. On the other hand, reasoning seems to be different from participant to participant. Moreover, the content of the problem (not only the meaning of the words but also their relations to one another), the scenario, the experimental instructions participants receive etc. matter just as much as the formal structure of the problem.

Specifically, several explanations on THOG reasoning have been put forward. Some, more specific ones, focused on analysing why it was such a complex task, such as the non-consequential reasoning task, or the theory of confusion. We have also developed two theories of human inference that have explained the reasoning behind the task: The Mental Models Theory and the Dual Process Theory. In general terms, both theoretical proposals defend that the 
behaviour of participants when they are reasoning could be reflected in a "competition" between "processes 1 and 2" (Evans, 2010, 2021) or between "intuition/deliberation or both" (Johnson-Laird, 2021), in the determination of the final answer.

Today we know the differential characteristics of both type 1 and type 2 processes, and it is also known that the majority of them are aspects related to intuition and/or reflexion, respectively (Evans \& Frankish, 2009; Evans \& Stanovich, 2013). However, how they behave is still unknown. It seems that occasionally, "type 1" processes, linked to intuition, are not as effective as traditionally thought (Johnson et al., 2016). In this sense, the "model of the three stages of dual process" has been put forward to analyse "what makes participants think and what triggers type 2 processing" (see Pennycook et al., 2015). Moreover, some recent theories on thinking and reasoning are studying the role of analytic reasoning in human morality, creativity or religious beliefs (see for example Pennycook, 2018).

How far have we come in recent years in the empirical research into the THOG and what repercussion has it had on the general study of reasoning? As regards empirical studies on the THOG, in the last decades the range of variables that seem to modulate the execution of the task has widened and new lines of research, developed beyond THOG reasoning, have opened up. In this vein, in the framework of the Mental Models theory, the study of cognitive illusions or the analysis of the role of content and empirical knowledge, explained through semantic and pragmatic modulation, are some of the open questions still studied today.

In the Dual Process Theory, a debated issue in THOG reasoning is as follows: when participants face the task, do they decide which designs are THOG without thinking, or do they think before deciding? (Martín \& Valiña, 2019). In general terms, is the execution explained from the activation of attentional heuristics associated to system 1 ? or are the culprits' hypothetical thinking processes linked to system 2? A key line of research related to this question is the study of individual differences, "essential components in dual process models" (Bonnefon \& Billaut, 2016: p. 222). The analysis of the influence they have on reasoning, differentiating aspects of participants as regards capacity and cognitive ability, together with mental disposition and styles of thinking, has also contributed to explaining THOG reasoning. In fact, research over the last decades on individual differences has shown that the analytical reasoning required by the experimental reasoning tasks, such as the THOG problem, is related to cognitive ability, thinking dispositions and a range of situational variables. The practical implications of these results in different fields, for example, that of education, politics, etc. have yet to be studied in depth (Evans, 2013; Stanovich, 2021b, 2021c).

Over the last decades new methodologies and measurement indices are being included in empirical research to contribute to a deeper understanding of the reasoning process (De Neys \& Osman, 2014). Mouse pointing method (for ex- 
ample Evans, 1996); eye-tracking (Ball et al., 2003; de Chantal et al., 2020; Macbeth et al., 2015; Thompson, 2021, among others); neural imaging studies, which analyze brain activity (see for example Bonatti et al., 2015; Goel, 2005, 2007; Goel et al., 2000; Goel \& Dolan, 2003, 2004; Goel et al., 2017; Heit, 2015) have recently contributed new empirical evidence and theoretical implications for cognitive theories of deductive reasoning (Goel \& Waechter, 2018).

In the nineties, Newstead et al. (1995) predicted that the THOG would be a task that would fascinate researches for a long time. But, why is it such a special problem?, "what is this thing called Thog?" (Manktelow, 2021). It is difficult to say. In 2003, we published a review of the THOG in which we studied this question. In this new work we have aimed to study how theoretical explanations and empirical research have advanced regarding this task. Nevertheless, researchers' interest in studying the THOG is not limited to understanding the problem per se. Empirical studies on this hypothetico-deductive reasoning task have also contributed to "illuminate the nature of human rationality" (Khemlani \& Johnson-Laird, 2017; see also Chater et al., 2018; Stanovich, 2021a; Stanovich et al., 2016; Viale, 2021) and to go deeper into "the nature of thought" (Newstead, 2003). In this sense, having more clues about the underlying mechanisms of reasoning, hypothetical thinking or decision making can contribute to a better understanding of people's behavior and why they sometimes make mistakes in different contexts of their daily life.

\section{Conflicts of Interest}

The authors declare no conflicts of interest regarding the publication of this paper.

\section{References}

Ball, L. J., Lucas, E. J., Miles, J. N. V., \& Gale, A. G. (2003). Inspection Times and the Selection Task: What Do Eye-Movements Reveal about Relevance Effects? The Quarterly Journal of Experimental Psychology, 56, 1053-1077. https://doi.org/10.1080/02724980244000729

Ball, L., \& De Neys, W. (2018). Dual Process Theory 2.0. Routledge. https://doi.org/10.4324/9781315204550

Bellini-Leite, S. C., \& Frankish, K. (2021). Bounded Rationality and Dual Systems. In R. Viale (Ed.), Routledge Handbook of Bounded Rationality (pp. 207-216). Routledge. https://doi.org/10.4324/9781315658353-13

Bonatti, L. L., Cherubini, P., \& Reverberi, C. (2015). Nothing New under the Sun, or the Moon, or Both. In V. Goel, G. Navarrete, I. A. Noveck, \& J. Prado (Eds.), The Reasoning Brain: The Interplay between Cognitive Neuroscience and Theories of Reasoning (pp. 131-134). Frontiers Media.

Bonnefon, J.-F., \& Billaut, E. (2016). Individual Differences in Reasoning beyond Ability and Disposition. In L. Macchi, M. Bagassi, \& R. Viale (Eds.), Cognitive Unconscious and Human Rationality (pp. 219-337). The MIT Press.

Bruckmaier, G., Krauss, S., Binder, K., Hilbert, S., \& Brunner, M. (2021). Tversky and Kahneman's Cognitive Illusions: Who Can Solve Them, and Why? Frontiers in Psy- 
chology, 12, Article ID: 584689. https://doi.org/10.3389/fpsyg.2021.584689

Carriedo, N., Moreno, S., Gutiérrez, F., \& García-Madruga, J. A. (1998). Modelos mentales en conjunciones, disyunciones y condicionales: Replicación de un estudio de Rips. In M. D. Valiña, \& M. J. Blanco (Eds.), I Jornadas de Psicología del Pensamiento. Actas (pp. 39-56). Cursos e Congresos da Universidade de Santiago de Compostela. No 114. Servicio de Publicacións da Universidade de Santiago de Compostela. http://hdl.handle.net/10347/11928

Chater, N., Felin, T., Funder, D. C., Gigerenzer, G., Koenderink, J. J., Krueger, J. I. et al. (2018). Mind, Rationality, and Cognition: An Interdisciplinary Debate. Psychonomic Bulletin \& Review, 25, 793-826. https://doi.org/10.3758/s13423-017-1333-5

Cordell, R. (1978). Mature Reasoning and Problem Solving (Unpublished Dissertation). University of Nottingham.

de Chantal, P.-L., Newman, I. R., Thompson, V., \& Markovits, H. (2020). Who Resists Belief-Biased Inferences? The Role of Individual Differences in Reasoning Strategies, Working Memory, and Attentional Focus. Memory \& Cognition, 48, 655-671. https://doi.org/10.3758/s13421-019-00998-2

De Neys, W., \& Osman, M. (Eds.) (2014). New Approaches in Reasoning Research. Psychology Press. https://doi.org/10.4324/9781315879857

Evans, J. St. B. T. (1972a). Interpretation and Matching Bias in a Reasoning Task. Quarterly Journal of Experimental Psychology, 24, 193-199. https://doi.org/10.1080/00335557243000067

Evans, J. St. B. T. (1972b). Reasoning with Negatives. British Journal of Psychology, 63, 213-219. https://doi.org/10.1111/j.2044-8295.1972.tb02102.x

Evans, J. St. B. T. (1977). Linguistic Factors in Reasoning. Quarterly Journal of Experimental Psychology, 29, 297-306. https://doi.org/10.1080/14640747708400605

Evans, J. St. B. T. (1982). The Psychology of Deductive Reasoning. Routledge.

Evans, J. St. B. T. (1984). Heuristic and Analytic Processes in Reasoning. British Journal of Psychology, 75, 541-468. https://doi.org/10.1111/j.2044-8295.1984.tb01915.x

Evans, J. St. B. T. (1989). Bias in Human Reasoning: Causes and Consequences. Erlbaum.

Evans, J. St. B. T. (1996). Deciding before You Think: Relevance and Reasoning in the Selection Task. British Journal of Psychology, 87, 223-240.

https://doi.org/10.1111/j.2044-8295.1996.tb02587.x

Evans, J. St. B. T. (2000). Thinking and believing. In J. A. García-Madruga, N. Carriedo, \& M. J. González-Labra (Eds.), Mental Models in Reasoning (pp. 41-55). UNED (Universidad Nacional de Educación a Distancia) Ediciones.

Evans, J. St. B. T. (2003). In Two Minds: Dual-Process Accounts of Reasoning. Trends in Cognitive Sciences, 7, 454-459. https://doi.org/10.1016/j.tics.2003.08.012

Evans, J. St. B. T. (2004). History of the Dual Process Theory of Reasoning. In K. Manktelow, \& M. Ch. Chung (Eds.), Psychology of Reasoning. Theoretical and Historical Perspectives (pp. 241-266). Routledge.

Evans, J. St. B. T. (2006). The Heuristic-Analytic Theory of Reasoning: Extension and Evaluation. Psychonomic Bulletin \& Review, 13, 378-395. https://doi.org/10.3758/BF03193858

Evans, J. St. B. T. (2007). Hypothetical Thinking: Dual Processes in Reasoning and Judgement. Psychology Press.

Evans, J. St. B. T. (2008). Dual-Processing Accounts of Reasoning, Judgment and Social Cognition. Annual Review of Psychology, 59, 255-278. 
https://doi.org/10.1146/annurev.psych.59.103006.093629

Evans, J. St. B. T. (2010). Thinking Twice: Two Minds in One Brain. Oxford University Press.

Evans, J. St. B. T. (2012). Dual-Process Theories of Deductive Reasoning: Facts and Fallacies. In K. J. Holyoak, \& R. G. Morrison (Eds.), The Oxford Handbook of Thinking and Reasoning (pp. 115-133). Oxford University Press. https://doi.org/10.1093/oxfordhb/9780199734689.013.0008

Evans, J. St. B. T. (2013). Reasoning, Rationality and Dual Processes. Selected Works of Jonathan St. B. T. Evans. Psychology Press. https://doi.org/10.4324/9781315886268

Evans, J. St. B. T. (2017). A Brief History of the Wason Selection Task. In N. Galbraith, E. Lucas, \& D. E. Over (Eds.), The Thinking Mind. A Festschrift for Ken Manktelow (pp. 1-14). Psychology Press.

Evans, J. St. B. T. (2018). Dual Process Theories. In L. J. Ball, \& V. A. Thompson (Eds.), The Routledge International Handbook of Thinking and Reasoning (pp. 151-166). Routledge.

Evans, J. St. B. T. (2019). Hypothetical Thinking. Dual Processes in Reasoning and Judgement. Psychology Press. https://doi.org/10.4324/9780367823832

Evans, J. St. B. T. (2021). Bounded Rationality, Reasoning and Dual Processing. In R. Viale (Ed.), Routledge Handbook of Bounded Rationality (pp. 185-195). Routledge. https://doi.org/10.4324/9781315658353-11

Evans, J. St. B. T., \& Stanovich, K. E. (2013). Dual-Process Theories of Higher Cognition: Advancing the Debate. Perspectives on Psychological Science, 8, 223-241. https://doi.org/10.1177/1745691612460685

Evans, J. St. B. T., \& Frankish, K. (Eds.) (2009). In Two Minds: Dual Processes and Beyond. Oxford University Press.

https://doi.org/10.1093/acprof:oso/9780199230167.001.0001

Evans, J. St. B. T., Handley, S. J., Neilens, H., \& Over, D. (2008). Understanding Causal Conditionals: A Study of Individual Differences. Quarterly Journal of Experimental Psychology, 61, 1291-1297. https://doi.org/10.1080/17470210802027961

Evans, J. St. B. T., Newstead, S. E., \& Byrne, R. M. J. (1993). Human Reasoning: The Psychology of Deduction. Psychology Press.

Evans, J. St. B. T., \& Over, D. E. (1996). Rationality and Reasoning. Psychology Press.

Evans, J. St. B. T., Over, S. E., \& Handley, S. (2003). Conditionals and Conditional Probability. Journal of Experimental Psychology. Learning Memory and Cognition, 29, 321-335. https://doi.org/10.1037/0278-7393.29.2.321

Frankish, K., \& Evans, J. St. B. T. (2009). The Duality of Mind: An Historical Perspective. In J. St. B. T. Evans, \& K. Frankish (Eds.), In Two Minds: Dual Processes and Beyond (pp. 1-30). Oxford University Press.

https://doi.org/10.1093/acprof:oso/9780199230167.003.0001

Girotto, V., \& Legrenzi, P. (1989). Mental Representation and Hypothetico-Deductive Reasoning: The Case of the THOG Problem. Psychological Research, 51, 129-135. https://doi.org/10.1007/BF00309308

Girotto, V., \& Legrenzi, P. (1993). Naming the Parents of the THOG: Mental Representation and Reasoning. The Quarterly Journal of Experimental Psychology, 46A, 701-713. https://doi.org/10.1080/14640749308401034

Goel, V. (2005). Cognitive Neuroscience of Deductive Reasoning. In K. J. Holyoak, \& R. G. Morrison (Eds.), The Cambridge Handbook of Thinking and Reasoning (pp. 475-492). Cambridge University Press. 
Goel, V. (2007). The Anatomy of Deductive Reasoning. Trends in Cognitive Science, 11, 435-441. https://doi.org/10.1016/j.tics.2007.09.003

Goel, V., \& Dolan, R. J. (2003). Explaining Modulation of Reasoning by Belief. Cognition, 87, B11-B22. https://doi.org/10.1016/S0010-0277(02)00185-3

Goel, V., \& Dolan, R. J. (2004). Differential Involvement of Left Prefrontal Cortex in Inductive and Deductive Reasoning. Cognition, 93, B109-B121. https://doi.org/10.1016/j.cognition.2004.03.001

Goel, V., Buchel, C., Frith, C., \& Dolan, J. (2000). Dissociation of Mechanisms Underlying Syllogistic Reasoning. Neuroimage, 12, 504-514. https://doi.org/10.1006/nimg.2000.0636

Goel, V., Navarrete, G., Noveck, I. A., \& Prado, J. (2017). The Reasoning Brain: The Interplay between Cognitive Neuroscience and Theories of Reasoning. Frontiers in Human Neuroscience, 10, Article No. 673. https://doi.org/10.3389/fnhum.2016.00673

Goel, V., \& Waechter, R. (2018). Inductive and Deductive Reasoning: Integrating Insights from Philosophy, Psychology, and Neuroscience. In L. J. Ball, \& V. A. Thompson (Eds.), The Routledge International Handbook of Thinking and Reasoning (pp. 218-247). Routledge.

Griggs, R. A. (1983). The Role of Problem Content in the Selection Task and THOG Problem. In J. St. B. T. Evans (Ed.), Thinking and Reasoning: Psychological Approaches (pp. 16-43). Routledge \& Kegan Paul.

Griggs, R. A., \& Cox, J. R. (1982). The Elusive Thematic-Materials Effect in Wason's Selection Task. British Journal of Psychology, 73, 407-420.

https://doi.org/10.1111/j.2044-8295.1982.tb01823.x

Griggs, R. A., Koenig, C. S., \& Alea, N. L. (2001). De-Confusing the THOG Problem: The Pythagorean Solution. The Quarterly Journal of Experimental Psychology, 54A, 921-933. https://doi.org/10.1080/713755998

Griggs, R. A., \& Newstead, S. E. (1982). The Role of Problem Structure in a Deductive Reasoning Task. Journal of Experimental Psychology: Learning, Memory and Cognition, 8, 297-307. https://doi.org/10.1037/0278-7393.8.4.297

Griggs, R. A., \& Newstead, S. E. (1983). The Source of Intuitive Errors in Wason's THOG Problem. British Journal of Psychology, 74, 451-459. https://doi.org/10.1111/j.2044-8295.1983.tb01877.x

Griggs, R. A., Platt, R. D., Newstead, S. E., \& Jackson, S. L. (1998). Attentional Factors in a Disjunctive Reasoning Task. Thinking and Reasoning, 4, 1-14. https://doi.org/10.1080/135467898394229

Heit, E. (2015). Brain Imaging, forward Inference, and Theories of Reasoning. Frontiers in Human Neuroscience, 8, Article No. 1056. https://doi.org/10.3389/fnhum.2014.01056

Johnson, E. D., Tubau, E., \& De Neys, W. (2016) The Doubting System 1: Evidence for Automatic Substitution Sensitivity. Acta Psychologica, 164, 56-64.

https://doi.org/10.1016/j.actpsy.2015.12.008

Johnson-Laird, P. N. (1983). Mental Models. Towards a Cognitive Science of Language, Inference and Consciousness. Cambridge University Press.

Johnson-Laird, P. N. (2000). The Current State of the Mental Model Theory. In J. A. García-Madruga, N. Carriedo, \& M. J. González-Labra (Eds.), Mental Models in Reasoning (pp. 17-39). UNED Ediciones.

Johnson-Laird, P. N. (2006). Mental Models, Sentential Reasoning, and Illusory Inferences. Advances in Psychology, 138, 27-51. 
https://doi.org/10.1016/S0166-4115(06)80026-9

Johnson-Laird, P. N. (2012). Inference with Mental Models. In K. J. Holyoak, \& R. G. Morrison (Eds.), The Oxford Handbook of Thinking and Reasoning (pp. 134-154). Oxford University Press. https://doi.org/10.1093/oxfordhb/9780199734689.013.0009

Johnson-Laird, P. N. (2013). The Mental Models Perspective. In D. Reisberg (Ed.), The Oxford Handbook of Cognitive Psychology (pp. 650-667). Oxford University Press. https://doi.org/10.1093/oxfordhb/9780195376746.013.0041

Johnson-Laird, P. N. (2021). Models and Rational Deductions. In R. Viale (Ed.), Routledge Handbook of Bounded Rationality (pp. 217-227). Routledge. https://doi.org/10.4324/9781315658353-14

Johnson-Laird, P. N., \& Byrne, R. M. J. (1991). Deduction. Lawrence Erlbaum Associates, Inc.

Johnson-Laird, P. N., \& Byrne, R. M. J. (1992). Modal Reasoning, Models, and Manktelow and Over. Cognition, 43, 173-182. https://doi.org/10.1016/0010-0277(92)90061-L

Johnson-Laird, P. N., \& Byrne, R. M. J. (2002). Conditionals: A Theory of Meaning, Pragmatics and Inference. Psychological Review, 109, 646-678. https://doi.org/10.1037/0033-295X.109.4.646

Johnson-Laird, P. N., Byrne, R. M. J., \& Schaeken, W. S. (1992). Propositional Reasoning by Model. Psychological Review, 99, 418-439. https://doi.org/10.1037/0033-295X.99.3.418

Johnson-Laird, P. N., Goodwin, G. P., \& Khemlani, S. S. (2018). Mental Models and Reasoning. In L. J. Ball, \& V. A. Thompson (Eds.), The Routledge International Handbook of Thinking and Reasoning (pp. 346-365). Routledge.

Johnson-Laird, P. N., \& Khemlani, S. S. (2013). Toward a Unified Theory of Reasoning. Psychology of Learning and Motivation, 59, 1-42. https://doi.org/10.1016/B978-0-12-407187-2.00001-0

Johnson-Laird, P. N., Legrenzi, P., \& Legrenzi, M. S. (1972). Reasoning and a Sense of Reality. British Journal of Psychology, 63, 395-400. https://doi.org/10.1111/j.2044-8295.1972.tb01287.x

Johnson-Laird, P. N., Lodstein, M., \& Byrne, R. M. J. (2012). The Consistency of Disjunctive Assertions. Memory \& Cognition, 40, 769-778. https://doi.org/10.3758/s13421-012-0188-2

Johnson-Laird, P. N., Quelhas, A. C., \& Rasga, C. (2021). The Mental Model Theory of Free Choice Permission and Paradoxical Disjunctive Inferences. Journal of Cognitive Psychology, 33, 951-973. https://doi.org/10.1080/20445911.2021.1967963

Johnson-Laird, P. N., \& Savary, F. (1996). Illusory Inferences about Probabilities. Acta Psychologica, 93, 69-90. https://doi.org/10.1016/0001-6918(96)00022-4

Johnson-Laird, P. N., \& Savary, F. (1999). Illusory Inferences: A Novel Class of Erroneous Deductions. Cognition, 71, 191-229. https://doi.org/10.1016/S0010-0277(99)00015-3

Khemlani, S. S., \& Johnson-Laird, P. N. (2009). Disjunctive Illusory Inferences and how to Eliminate them. Memory \& Cognition, 37, 615-623. https://doi.org/10.3758/MC.37.5.615

Khemlani, S. S., \& Johnson-Laird, P. N. (2017). Illusions in Reasoning. Minds \& Machines, 27, 11-35. https://doi.org/10.1007/s11023-017-9421-X

Khemlani, S. S., Orenes, I., \& Johnson-Laird, P. N. (2014). The Negation of Conjunctions, Conditionals and Disyunctions. Acta Psychologica, 151, 1-7.

https://doi.org/10.1016/j.actpsy.2014.05.004 
Koenig, C. S., \& Griggs, R. A. (2001). Elementary, My Dear Wason: The Role of Problem Representation in the THOG Task. Psychological Research, 65, 289-293. https://doi.org/10.1007/s004260100067

Koenig, C. S., \& Griggs, R. A. (2004a). Analogical Transfer in the THOG Task. The Quarterly Journal of Experimental Psychology, 57A, 557-570. https://doi.org/10.1080/02724980343000422

Koenig, C. S., \& Griggs, R. A. (2004b). Facilitation and Analogical Transfer in the THOG Task. Thinking and Reasoning, 10, 355-370. https://doi.org/10.1080/13546780342000070

Koenig, C. S., \& Griggs, R. A. (2011). Facilitation and Analogical Transfer on a Hypothetico-Deductive Reasoning Task. In K. Manktelow, D. Over, \& S. Elqayam (Eds.), The Science of Reason. A Festschrift for Jonathan ST. B. T. Evans (pp. 63-89). Psychology Press.

Koenig, C. S., Platt, R. D., \& Griggs, R. A. (2007). Using Dual-Process Theory and Analogical Transfer to Explain Facilitation on a Hypothetico-Deductive Reasoning task. Psychological Research, 71, 495-502. https://doi.org/10.1007/s00426-006-0046-6

López Astorga, M. (2014). A Formal Theory Can Explain Disjunctive Illusory Inferences. Círculo de Lingüística Aplicada a la Comunicación, 60, 122-143.

http://www.ucm.es/info/circulo/no60/lopez.pdf https://doi.org/10.5209/rev CLAC.2014.v60.47445

López Astorga, M. (2018). The Possibilities of Disjunction in the Mental Models Theory. Prometeica-Revista de Filosofía y Ciencias, 16, 26-32. https://doi.org/10.24316/prometeica.v0i16.207

López Astorga, M. (2019). Exclusividad y tipos de modelos de inferencias disyuntivas moduladas. Nóesis. Revista de Ciencias Sociales y Humanidades, 28, 185-195. https://doi.org/10.20983/noesis.2019.1.9

Macbeth, G., Razumiejczyk, E. Crivello, M. C., Bolzán, C., Pereyra Girardi, C. I., \& Campitelli, G. (2014). Mental Models for the Negation of Conjunctions and Disjunctions. Europe's Journal of Psychology, 10, 135-149. https://doi.org/10.5964/ejop.v10i1.696

Macbeth, G., Razumiejczyk, E. Crivello, M. C., \& Fioramonti, M. (2015). The Use of Eye-Tracking Technologies in Deductive Reasoning Research. International Journal of Engineering and Advanced Research Technology, 1, 47-51.

Manktelow, K. (2021). Beyond Reasoning. The Life, Times and Work of Peter Wason, Pioneering Psychologist. Routledge. https://doi.org/10.4324/9781003127963

Manktelow, K., \& Galbraith, N. (2012). Thinking and Reasoning. An Introduction to the Psychology of Reason, Judgment and Decision Making. Psychology Press. https://doi.org/10.4324/9780203115466

Marek, P., Griggs, R. A., \& Koenig, C. S. (2000). Reducing Cognitive Complexity in a Hypotetico-Deductive Reasoning Task. Thinking and Reasoning, 6, 253-265. https://doi.org/10.1080/13546780050114528

Martín, M., Seoane, G., Valiña, M. D., \& Ferraces, M. J. (1998). La importancia de las diferencias individuales en razonamiento disyuntivo. Libro de resúmenes II Congreso Iberoamericano de Psicología (pp. 567-568). Alpe Celter.

Martín, M., \& Valiña, M. D. (2002). Razonamiento Deductivo: Una aproximación al estudio de la disyunción. Revista de Psicología General y Aplicada, 55, 225-248.

Martín, M., \& Valiña, M. D. (2003). Dos décadas de investigación sobre el problema THOG: ¿una disyunción por resolver?. Revista de Psicología General y Aplicada, 56, 
21-43.

Martín, M., \& Valiña, M. D. (2019). Thinking about Wason's THOG Problem. In Book of Abstracts of the 21st Conference of the European Society for Cognitive Psychol$o g y$-ESCOP (p. 290). European Society for Cognitive Psychology.

Needham, W. P., \& Amado, C. A. (1995). Facilitation and Transfer with Narrative Thematic Versions of the THOG Task. Psychological Research, 58, 67-73.

Newstead, S. (2003). Peter Wason (1924-2003). Thinking \& Reasoning, 9, 177-184. https://doi.org/10.1080/13546780244000141

Newstead, S. E., \& Evans J. St. B. T. (Eds.) (1995). Perspectives on Thinking and Reasoning. Essays in Honour of Peter Wason. Lawrence Erlbaum Associates, Inc.

Newstead, S. E., Girotto, V., \& Legrenzi, P. (1995). The THOG Problem and Its Implications for Human Reasoning. In S. E. Newstead, \& J. St. B. T. Evans (Eds.), Perspectives on Thinking and Reasoning. Essays in Honour of Peter Wason (pp. 261-285). Lawrence Erlbaum Associates, Inc.

Newstead, S. E., Griggs, R. A., \& Warner, S. A. (1982). The Effects of Realism on Wason's THOG Problem. Psychological Research, 54, 299-305. https://doi.org/10.1007/BF01358267

Newstead; S. E., \& Griggs, R. A. (1992). Thinking about THOG: Sources of Error in a Deductive Reasoning Problem. Psychological Research, 54, 299-305.

https://doi.org/10.1007/BF01358267

O’Brien, D. P., Noveck, J. A., Davidson, G. M., Fish, S. M., Lea, R. B., \& Freitag, J. (1990). Sources of Difficulty in Deductive Reasoning: the THOG Task. The Quarterly Journal of Experimental Psychology, 42, 329-351. https://doi.org/10.1080/14640749008401225

Oberauer, K., Süß, H.-M., Wilhelm, O., \& Sander, N. (2007). Individual Differences in Working Memory Capacity and Reasoning Ability. In A. R. A. Conway, C. Jarrold, M. J. Kane, A. Miyake, \& J. N. Towse (Eds.), Variation in Working Memory (pp. 49-75). Oxford University Press. https://doi.org/10.1093/acprof:oso/9780195168648.003.0003

Pennycook, G. (Ed.) (2018). The New Reflectionism in Cognitive Psychology. Why Reason Matters. Routledge. https://doi.org/10.4324/9781315460178

Pennycook, G., Fugelsang, J. A., \& Koehler, D. J. (2015). Everyday Consequences of Analytic Thinking. Current Directions in Psychological Science, 24, 425-432. https://doi.org/10.1177/0963721415604610

Pohl, R. F. (Ed.) (2017). Cognitive Illusions. Intriguing Phenomena in Thinking, Judgment and Memory. Routledge.

Quelhas, A. C., \& Johnson-Laird, P. N. (2017). The Modulation of Disjunctive Assertions. The Quarterly Journal of Experimental Psychology, 70, 703-717. https://doi.org/10.1080/17470218.2016.1154079

Quelhas, A. C., Johnson-Laird, P. N., \& Juhos, C. (2010). The Modulation of Disjunctive Assertions and Its Effects on Reasoning. The Quarterly Journal of Experimental Psychology, 63, 1716-1739. https://doi.org/10.1080/17470210903536902

Quelhas, A. C., Rasga, C., \& Johnson-Laird, P. N. (2019). The Analytic Truth and falsity of Disjunctions. Cognitive Science, 43, Article ID: e12739.

https://doi.org/10.1111/cogs.12739

Rhodes, S., Galbraith, N., \& Manktelow, K. (2020). Delusional Rationality. In S. Elqayam, I. Douven, J. St. B. T. Evans, \& N. Cruz (Eds.), Logic and Uncertainty in the Human Mind. A Tribute to David E. Over (pp. 178-191). Routledge. https://doi.org/10.4324/9781315111902-11

Ricco, R. B., Koshino, H., Sierra, A. N., Bonsel, J., Von Monteza, J. V., \& Owens, D. 
(2020). Individual differences in Analytical Thinking and Complexity of Inference in Conditional Reasoning. Thinking \& Reasoning, 27, 319-349. https://doi.org/10.1080/13546783.2020.1794958

Rojas-Barahona, C. A., Moreno-Ríos, S., García-Madruga, J. A., \& Förster, C. E. (2021). Content of Relationships, Number of Alternatives and Working Memory Capacity in Conditional Inferences. Current Psychology. https://doi.org/10.1007/s12144-021-01966-3

Sablé-Meyer, M., \& Mascarenhas, S. (2021). Indirect Illusory Inferences from Disjunction: A New Bridge between Deductive Inference and Representativeness. Review of Philosophy and Psychology. https://doi.org/10.1007/s13164-021-00543-8

Santamaría, C., \& Johnson-Laird, P. N. (1998). Ilusiones en el razonamiento proposicional. In M. D. Valiña \& M. J. Blanco (Eds.), I Jornadas de Psicología del Pensamiento. Actas (pp. 57-93). Cursos y Congresos de la Universidad de Santiago de Compostela. No. 114. Servicio de Publicacións da Universidade de Santiago de Compostela.

Santamaría, C., \& Johnson-Laird, P. N. (2000). An Antidote to Illusory Inferences. Thinking \& Reasoning, 6, 313-333. https://doi.org/10.1080/135467800750038157

Schreiber, J. M. (2014). Cognitive Processes Associated with the Perception of Randomness. Journal of Educational and Developmental Psychology, 4, 84-104. https://doi.org/10.5539/jedp.v4n1p84

Seoane, G., Rodríguez, M. S., \& Valiña, M. D. (2002). Diferencias individuales en razonamiento condicional: Predictores psicométricos. Metodología de las Ciencias del Comportamiento, Volumen especial, 509-511.

Seoane, G., Valiña, M. D., Ferraces, M. J., \& Martín, M. (1997). Comparing Measures of Individual Diferences in Performance of Conditional Reasoning. In C. Arce, \& G. Seoane (Eds.), Proceedings of the 10th European Meeting of the Psychometric Society (p. 163). University of Santiago de Compostela.

Seoane, G., Valiña, M. D., Rodríguez, M. S., Martín, M., \& Ferraces, M. J. (2007). Diferencias individuales en razonamiento hipotético-deductivo: Importancia de la flexibilidad y de las habilidades cognitivas. Psicothema, 19, 206-211. http://hdl.handle.net/10347/18520

Shafir, E. B., \& Tversky, A. (1992). Thinking through Uncertainty: Nonconsequential Reasoning and Choice. Cognitive Psychology, 24, 449-474. https://doi.org/10.1016/0010-0285(92)90015-T

Sloman, S. A. (1996). The Empirical Case for Two Systems of Reasoning. Psychological Bulletin, 119, 3-22. https://doi.org/10.1037/0033-2909.119.1.3

Smyth, M. M., \& Clark, S. E. (1986). My Half-Sister Is a THOG: Strategic Processes in a Reasoning Task. British Journal of Psychology, 77, 275-287. https://doi.org/10.1111/j.2044-8295.1986.tb02002.x

Stanovich, K. E. (1999). Who Is Rational? Studies of Individual Differences in Reasoning. Psychology Press. https://doi.org/10.4324/9781410603432

Stanovich, K. E. (2004). The Robot's Rebellion: Finding Meaning in the Age of Darwin. University of Chicago Press. https://doi.org/10.7208/chicago/9780226771199.001.0001

Stanovich, K. E. (2009). What Intelligence Tests Miss. The Psychology of Rational Thought. Yale University Press.

Stanovich, K. E. (2011). Rationality and the Reflective Mind. Oxford University Press. https://doi.org/10.1093/acprof:oso/9780195341140.001.0001

Stanovich, K. E. (2018). Miserliness in Human Cognition: The Interaction of Detection, Override and Mindware. Thinking \& Reasoning, 24, 423-444. 
https://doi.org/10.1080/13546783.2018.1459314

Stanovich, K. E. (2021a). Why Humans Are Cognitive Misers and What It Means for the Great Rationality Debate. In R. Viale (Ed.), Routledge Handbook of Bounded Rationality (pp. 196-206). Routledge. https://doi.org/10.4324/9781315658353-12

Stanovich, K. E. (2021b). The Bias That Divide Us. The Science and Politics of Myside Thinking. The MIT Press. https://doi.org/10.7551/mitpress/13367.001.0001

Stanovich, K. E. (2021c). The Irrational Attempt to Impute Irrationality to One's Political Opponents. In M. Hannon, \& J. de Ridder (Eds.), Routledge Handbook of Political Epistemology. Routledge. https://doi.org/10.4324/9780429326769-33

Stanovich, K. E., \& West, R. F. (1997). Reasoning Independently of Prior Belief and Individual Differences in Actively Open-Minded Thinking. Journal of Educational Psychology, 89, 342-357. https://doi.org/10.1037/0022-0663.89.2.342

Stanovich, K. E., \& West, R. F. (1998). Individual Differences in Rational Thought. Journal of Experimental Psychology: General, 127, 161-188.

https://doi.org/10.1037/0096-3445.127.2.161

Stanovich, K. E., \& West, R. F. (2000). Individual Differences in Reasoning: Implications for the Rationality Debate? Behavioral and Brain Sciences, 23, 645-665. https://doi.org/10.1017/S0140525X00003435

Stanovich, K. E., \& Toplak, M. E. (2012). Defining Features versus Incidental Correlates of Type 1 and Type 2 Processing. Mind \& Society, 11, 3-13.

https://doi.org/10.1007/s11299-011-0093-6

Stanovich, K. E., Sá, W. C., \& West, R. F. (2004). Individual Differences in Thinking, Reasoning and Decision Making. In J. P. Leighton, \& R. J. Sternberg (Eds.), The Nature of Reasoning (pp. 375-409). Cambridge University Press. https://doi.org/10.1017/CBO9780511818714.014

Stanovich, K. E., West, R. F., \& Toplak, M. E. (2011). Individual Differences as Essential Components of Heuristics and Biases Research. In K. Manktelow, D. Over, S. Elqayam (Eds.), The Science of Reason. A Festschrift for Jonathan ST. B. T. Evans (pp. 355-396). Psychology Press.

Stanovich, K. E., West, R. F., \& Toplak, M. E. (2016). The Rationality Quotient: Toward a Test of Rational Thinking. The MIT Press. https://doi.org/10.7551/mitpress/9780262034845.001.0001

Stanovich, K. E., West, R. F., \& Toplak, M. E. (2017). Toward a Rationality Quotient (RQ): The Comprehensive Assessment of Rational Thinking (CART). In N. Galbraith, E. Lucas, \& D. Over (Eds). The Thinking Mind: A Festschrift for Ken Manktelow (pp. 202-221). Routledge. https://doi.org/10.7551/mitpress/9780262034845.003.0004

Thompson, V. A. (2021). Eye-Tracking IQ: Cognitive Capacity and Strategy Use on a Ratio-Bias Task. Cognition, 208, Article ID: 104523.

https://doi.org/10.1016/j.cognition.2020.104523

Thompson, V. A., \& Markovits, H. (2021). Reasoning Strategy vs Cognitive Capacity as Predictors of Individual Differences in Reasoning Performance. Cognition, 217, Article ID: 104866. https://doi.org/10.1016/j.cognition.2021.104866

Toplak, M. E., \& Rizeq, (2020). Development of Judgment, Decision Making and Rationality. Oxford Research Encyclopedia of Psychology. https://doi.org/10.1093/acrefore/9780190236557.013.542

Toplak, M. E., \& Stanovich, K. E. (2002). The Domain Specificity and Generality of Disjunctive Reasoning: Searching for a Generalizable Critical Thinking Skill. Journal of Educational Psychology, 94, 197-209. https://doi.org/10.1037/0022-0663.94.1.197 
Tversky, A., \& Shafir, E. B. (1992). The Disjunction Effect in Choice under Uncertainty. Psychological Science, 3, 305-310. https://doi.org/10.1111/j.1467-9280.1992.tb00678.x

Valiña, M. D., \& Martín, M. (2016). The Influence of Semantic and Pragmatic Factors in Wason's Selection Task: State of the Art. Psychology, 7, 925-940. https://doi.org/10.4236/psych.2016.76094

Valiña, M. D., Seoane, G., Ferraces, M. J., \& Martín, M. (1995). Tarea de selección de Wason: Un estudio de las diferencias individuales. Psicothema, 7, 641-653.

Valiña, M. D., Seoane, G., Ferraces, M. J., \& Martín, M. (2000). Conditional Reasoning: The Importance of Individual Differences. In J. A. García-Madruga, N. Carriedo, \& M. J. González-Labra (Eds.), Mental Models in Reasoning (pp. 249-267). UNED (Universidad Nacional de Educación a Distancia) Ediciones.

Valiña, M. D., Seoane, G., Martín, M., Rodríguez, M. S., \& Ferraces, M. J. (2003). Individual Differences in deductive Reasoning: Formal and Thematic Wason's THOG Problems. In T. Bajo, \& J. Lupiáñez (Eds.), XIII Conference of the European Society for Cognitive Psychology (p. 510). Universidad de Granada. http://hdl.handle.net/10347/10065

Viale, R. (Ed.) (2021). Routledge Handbook of Bounded Rationality. Routledge. https://doi.org/10.4324/9781315658353

Wason, P. C. (1966). Reasoning. In B. M. Foss (Ed.), New Horizons in Psychology (pp. 135-151). Harmondsworth, Penquin.

Wason, P. C. (1968). Reasoning about a Rule. Quarterly Journal of Experimental Psychology, 20, 273-281. https://doi.org/10.1080/14640746808400161

Wason, P. C. (1977). Self-Contradictions. In P. N. Johnson-Laird, \& P. C. Wason (Eds.), Thinking: Readings in Cognitive Science (pp. 114-128). Cambridge University Press.

Wason, P. C. (1978). Hypothesis Testing and Reasoning. Unit 25, Block 4, Cognitive Psychology. Open University Press.

Wason, P. C., \& Brooks, P. G. (1979). THOG: The Anatomy of a Problem. Psychological Research, 41, 79-90. https://doi.org/10.1007/BF00309425

Wason, P. C., \& Evans, J. St.B. T. (1975). Dual Processes in Reasoning? Cognition, 3, 141-154. https://doi.org/10.1016/0010-0277(74)90017-1

Wason, P. C., \& Shapiro, D. A. (1971). Natural and Contrived Experience in a Reasoning Problem. Quarterly Journal of Experimental Psychology, 23, 63-71. https://doi.org/10.1080/00335557143000068

West, R. F., Toplak, M. E., \& Stanovich, K. E. (2008). Heuristics and Biases as Measures of Critical Thinking: Associations with Cognitive Ability and Thinking Dispositions. Journal of Educational Psychology, 100, 930-941. https://doi.org/10.1037/a0012842

Yin, P., Sun, J., \& Wang, M. (2000). The Relative Difficulty of Negations of Conjunctions and Disjunctions-A Mental Model Perspective. Cognitive Processing, 22, 65-76. https://doi.org/10.1007/s10339-020-01004-3 